\title{
An Exploration of Transportation Source Contribution to Noise Levels Near an Airport
}

\author{
Laura Margaret Dale ${ }^{1}$, Maximilien Debia ${ }^{2}$, Olivier Christian Mudaheranwa ${ }^{2}$, Céline Plante ${ }^{3} \&$ Audrey \\ Smargiassi ${ }^{2,4}$ \\ ${ }^{1}$ McGill School of Environment, McGill University, Montréal, Canada \\ ${ }^{2}$ Département de santé environnementale et de santé au travail, Université de Montréal, Montréal, Canada \\ ${ }^{3}$ Direction de la santé publique de l'Agence de la santé et des services sociaux de Montréal, Montréal, Canada \\ ${ }^{4}$ Institut National de Santé Publique du Québec, Montréal, Canada \\ Correspondance: Audrey Smargiassi, Département de santé environnementale et de santé au travail, Université \\ de Montréal, Montréal, QC., H3C 3J7, Canada. Tel: 1-514-343-6111 ext. (38528). E-mail: \\ audrey.smargiassi@umontreal.ca
}

Received: October 24, 2013 Accepted: November 23, 2013 Online Published: December 20, 2013

doi:10.5539/ep.v3n1p73 URL: http://dx.doi.org/10.5539/ep.v3n1p73

\begin{abstract}
Our study aimed to explore the contribution of transportation activities to environmental noise levels near an international airport. A-weighted equivalent and maximum noise levels (LAeq, 6hr; LAmax, 6hr; LAeq, 1hr) were monitored at six different locations characterized by their varying proximity to transportation sources. The values for LAeq, $6 \mathrm{hr}$ were in the range of 55.3 to $75.6 \mathrm{dBA}$, and LAmax, $6 \mathrm{hr}$ were 4.1 to $9.1 \mathrm{dBA}$ higher than their respective LAeq, $6 \mathrm{hr}$ values. Standard deviations were low across all sites and indicators (0.20-1.83 dBA). We found that at each site measured, the WHO's noise exposure guidelines of $55 \mathrm{dBA}$ were exceeded, including sites located in residential areas or near a school. In one residential area near the airport (but away from other transportation sources), noise levels were $63.1 \mathrm{dBA}$. In another residential area closer to the airport, the contribution of airport noise to environmental noise was estimated to be $72.3 \mathrm{dBA}$, which is roughly as high as the contribution of two other transportation sources (highway and railway) in this area. In proximity to the Montreal International Airport, noise levels may have been elevated by airport operations and by noise from flights, the latter of which likely has a weaker effect on, and the former of which is unlikely to contribute to, noise levels at locations farther from the airport. At farther distances however, aircraft passages raised noise levels to a greater extent above those levels when no flight was passing, reflecting a sporadic quality of aircraft noise.
\end{abstract}

Keywords: environmental noise, urban, residential, traffic, airport, highway, railway

\section{Introduction}

An exposure quantification of urban pollutants is an important step in understanding the risks associated with their sources. One such pollutant, environmental noise, has been linked with several non-auditory malaises in both children and adults, including cognitive impairment (Stansfeld, Hygge, Clark, \& Alfred, 2010), cardiovascular effects (Stansfeld \& Crombie, 2011; Haralabidis et al., 2008), sleep disturbance (Perron, Tétreault, King, Plant, \& Smargiassi, 2012) and annoyance (Passchier-Vermeer \& Passchier, 2000).

Environmental noise refers to noise emitted from all sources except for that at industrial workplaces (Berglund, Lindvall, \& Schwela, 1999). The noise sources contributing to the most widespread health effects in people tend to be related to transportation activities, namely road, rail and air traffic. The impacts of various sources, even at equal levels, however, are not uniform. Studies suggest that features of air traffic noise, such as its intensity, variability and unpredictability may contribute to greater health outcomes compared to the relatively more constant noise emitted by road traffic. Increased cognitive impairment in children, for example, has been associated with aircraft, but not road traffic noise exposure (Stansfeld et al., 2005). Similarly, exposure to rail traffic noise has been shown to result in a lower annoyance response than that of both air and road traffic (Fields \& Walker, 1982). A greater understanding of each source's contribution to exposure levels is needed to better assess the health response in people. 
The present study measured and compared noise levels and variability at 6 sample sites characterized by their varying proximity to highway, airport and railway activities. The primary objective of this study was to explore the contribution of these transportation activities to environmental noise in the region of the Montreal airport.

\section{Method}

2.1 Sampling Sites

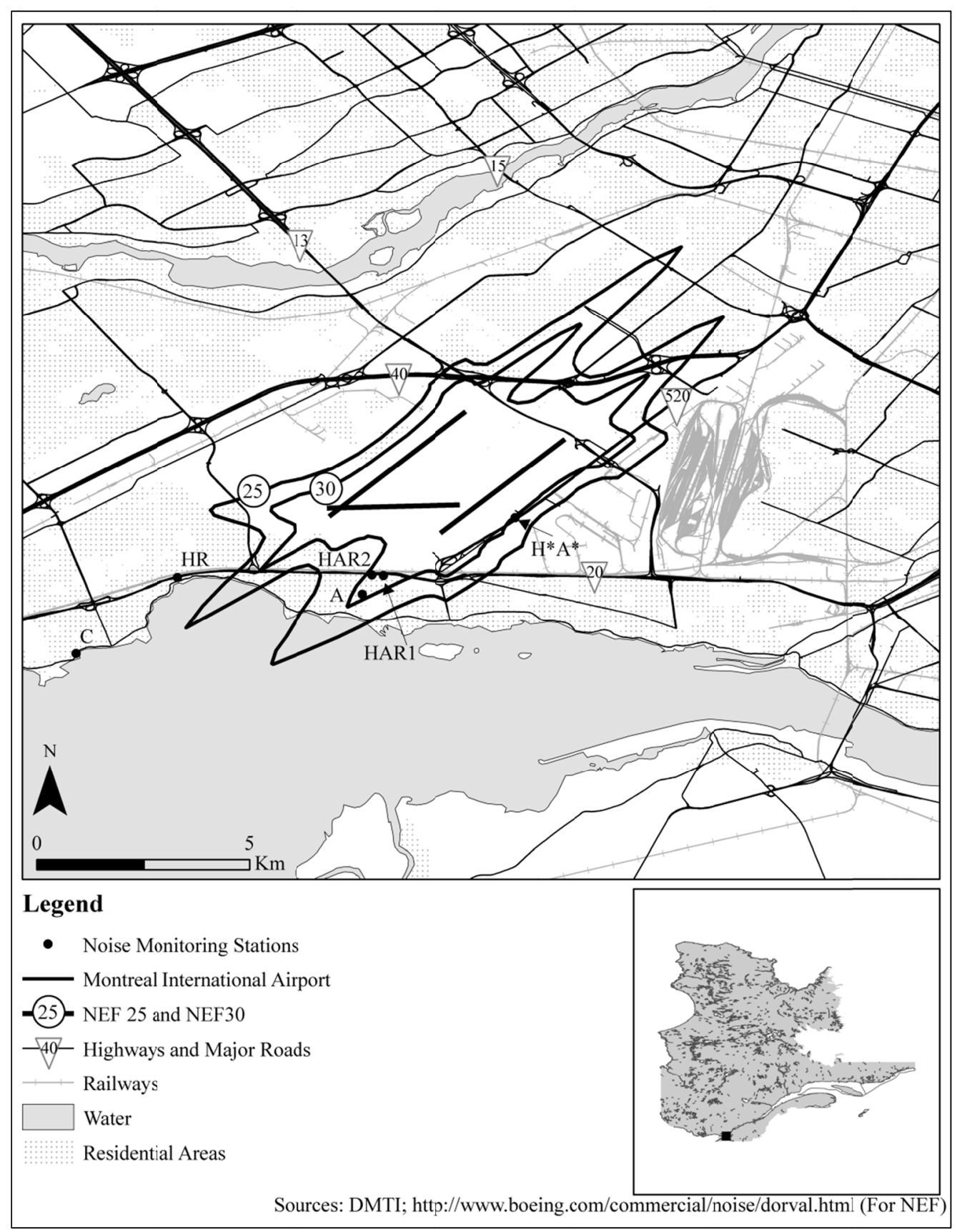

Figure 1. Map of sampling sites in Dorval City, Montreal Island

Sampling sites within Dorval, a city on the island of Montreal, were chosen based on NEF 30 and NEF 25 Noise Exposure Forecasts around the Montreal International Airport for the year 2009 (Boeing, 2011) (Figure 1). The NEF 30 zone refers to the area surrounding the airport in which there is a noise exposure forecast (NEF) value of 30. Values are calculated based on effective perceived noise levels for aircraft operations in order to encourage compatible land use in surrounding areas. The NEF 25 zone represents a lower level of noise exposure and thus 
corresponds to a wider contour, which surrounds that of the NEF 30 zone. The sampling sites are defined as follows:

- HAR1: the Highway + Airport NEF 30 + Railway site was located about $1400 \mathrm{~m}$ southwest of the Montreal International Airport, along the axis of its runways. It was within the NEF 30 zone and along the A20 highway.

- HAR2: the Highway + Airport NEF 30 + Railway site was located 200 m west of HAR1.

- HR: the Highway + Railway site was located along the A20 highway, outside the NEF 30 and NEF 25 zones.

- $\quad \mathbf{H}^{*} \mathbf{A} *$ : the Highway* + Airport NEF $25^{*}$ site was located along the Côte-de-Liesse Expressway, just outside of the NEF 30 zone but within the contours of the NEF 25 zone. It was about $650 \mathrm{~m}$ southeast of the airport's runways.

- A: the Airport NEF 30 site was situated about 2000 m southwest of the Montreal International Airport, along the axis of its runways. It was in a residential area within the NEF 30 zone and close to a school.

- C: The Control site was located in a residential area outside of both the NEF 30 and 25 zones.

Sites A and C were located in residential areas. Sites HAR1, HAR2 and HR were slightly outside their closest respective residential zones, but less than $50 \mathrm{~m}$ away at each location. Each of sites HAR1, HAR2, HR and $\mathrm{H}^{*} \mathrm{~A}^{*}$ were situated just off the curb of a highway access road. It was not possible to use the same highway for each of these four sites since the railway was always situated parallel to the A20 highway. The Highway* + Airport* site is thus labelled with two asterisks to draw attention to two considerations. The first is that the Côte-de-Liesse Expressway was selected for this site rather than the A20 highway, and the second is that this site was within the NEF 25 contours, but just outside the NEF 30 zone. Highway traffic flow data for the year 2010 suggests that the traffic flow at site $\mathrm{H}^{*} \mathrm{~A}^{*}$ (about 32000 vehicles) was roughly half of that at sites HR, HAR1 and HAR2 (in the range of 63000 to 75000 vehicles) (Transports Québec, 2010), thus the contribution of road traffic noise was assumed to be equal at sites HR, HAR1 and HAR2, but not at $\mathrm{H}^{*} \mathrm{~A}^{*}$.

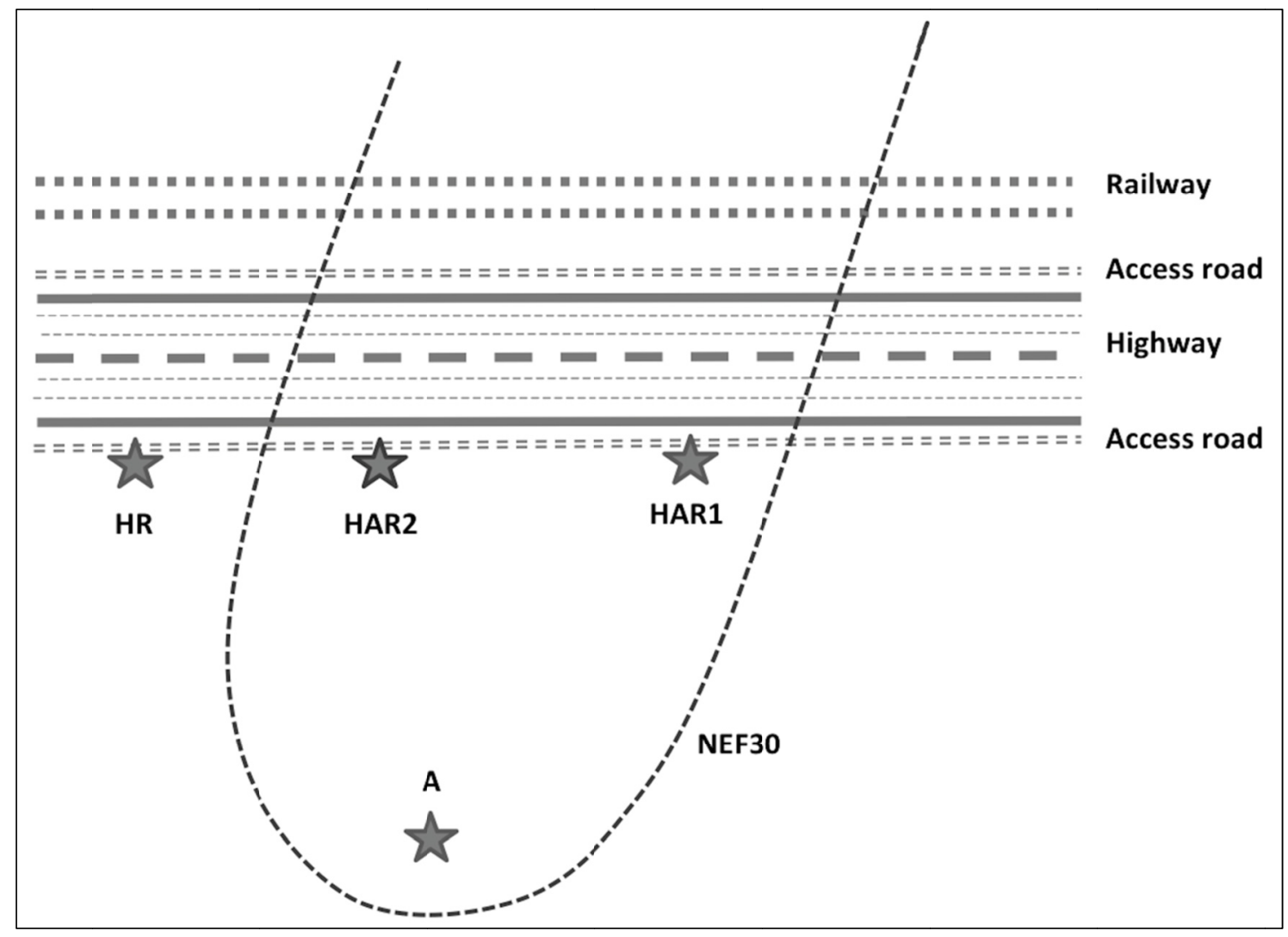

Figure 2. Schematic representation of sampling sites HR, HAR1, HAR2 and A 
At sites HR, HAR1 and HAR2, the railway track, freight trains and passenger trains were situated parallel to the A20 highway, north of the sampling locations (Figure 2). The distance from the highway to the railway was roughly $60 \mathrm{~m}$ at each of these sites and so the contribution of railway noise was assumed to be equal. At sites A, HAR1, HAR2, and $\mathrm{H}^{*} \mathrm{~A}^{*}$, samples were taken within visible range of passing aircrafts, within the NEF 25 or 30 zone.

\subsection{Sampling Strategy}

In the summer of 2012, sites HAR1, $\mathrm{H}^{*} \mathrm{~A}^{*}$, and A were sampled; in the fall of 2012, sampling was done at sites HAR2, HR and C. The two HAR sites were in the same area, but were termed HAR1 and HAR2 to differentiate between the times of their sampling campaigns, in the summer and fall, respectively. The replication of this measurement acted to ensure the representativity of the results for this zone, and that the seasonal variation in the data was negligible between the summer and fall sampling events.

Table 1. Days sampled at each site in 2012

\begin{tabular}{llllll}
\hline & Monday & Tuesday & Wednesday & Thursday & Friday \\
\hline HAR1 & July 30 & $\begin{array}{l}\text { Aug 7 } \\
\text { Aug 21 }\end{array}$ & & Aug 2 & \\
H*A* & Aug 6 & Aug 14 & Aug 22 & Aug 9 & \\
A & Aug 13 & July 31 & Aug 8 & Aug 16 & \\
HAR2 & Nov 5 & Nov 6 & Nov 7 & & Nov 9 \\
HR & Nov 12 & & Nov 14 & Nov 15 & Nov 16 \\
C & & & & Nov 22 & Nov 23 \\
\hline
\end{tabular}

Sites HAR1, HAR2, HR, $\mathrm{H}^{*} \mathrm{~A} *$ and A were sampled on four days from Monday to Friday over 6 hours (noon to $6 \mathrm{pm}$ ), and site $\mathrm{C}$ was sampled on two days over 6 hours (11am to $5 \mathrm{pm}$ ). Data was collected every minute to give a total of 360 measurements for each of 22 days of sampling. The distribution of sampling sites by day is shown in Table 1.

Samples were collected such that wind speed did not equal or exceed $5 \mathrm{~m} / \mathrm{s}$, humidity was much less than $90 \%$, there was no precipitation, and ambient temperatures were within the tolerable limits for the instruments used. No sampling was done on days with atypical noise events, such as construction and public work. At sites HAR1 and $\mathrm{A}$, a fieldworker recorded the times of aircraft passage over the sites in a notebook for consideration in the analysis. It was assumed that each flight lasted one minute over the site.

\subsection{Equipment}

(1) The Sound Level Meter: A Larson Davis SoundTrack LxT2 (Class 2) sound level meter was used to determine noise levels and the distribution of sound frequencies at the sites. The sound level meter was equipped with an anti-wind shield, and mounted on a tripod at a height of $1.5 \mathrm{~m}$ from the ground. The data was processed first by the firmware version 2.112 included in the sound level meter and then by the software Slm Utlity-G3 installed on a computer.

(2) The Calibrator: The sound level meter was calibrated at the beginning and end of each measurement with the Larson Davis CAL150 Sound Level Calibrator.

(3) The Air Velocity Meter: The TSI Model 8360-M-GB VelociCalc Plus Air Velocity Meter was used to monitor the wind speed, humidity and ambient temperature at each site.

\subsection{Analysis of Results}

Three sound level indicators were calculated: 1) LAeq, $6 \mathrm{hr}$, representing the A-weighted equivalent sound energy during 6 hours of sampling; 2) LAeq, $1 \mathrm{hr}$, representing the A-weighted equivalent sound energy over one hour of sampling; and 3) LAmax, 6hr, which expresses the A-weighted peak sound events within the 6-hour sampling interval, usually generated by a particular source such as the passing of an aircraft or a large truck.

Student's t-tests were used to assess the differences in the means for both LAeq, 6hr and LAmax, 6hr between sites HAR1 and HAR2. We used an analysis of variance (ANOVA) to test the differences in means for these same indicators among all sites. This was followed by a post hoc pairwise comparison with a Bonferroni 
adjustment. There was not enough data in the samples to test for the normality of the distributions. However, normality was assumed based on previous data obtained on Laeq, $24 \mathrm{~h}$ from another sampling campaign (84 sites including similar locations in Montréal) which were close to normal (S. Goudreau, personal communication).

LAeq, $6 \mathrm{hr}$ and LAmax, 6hr values were also calculated for periods when aircrafts were (LAeq, P \& LAmax, P) or were not passing (LAeq, NP \& LAmax, NP) for sites HAR1 and A. These calculations were made based on averages of unlogged minute LAeq data obtained from the sound level meter. Data on equivalent sound levels that corresponded to different frequency components was also obtained from the sound level meter. The unlogged form of this data was expressed as a percentage of the overall equivalent sound level at each site to illustrate the relative frequency distribution.

Lastly, the contribution of airport noise to site HAR (using compiled data from HAR1 and HAR2) was calculated using the following equation, as described by Barron (2003):

$$
L_{A}=10 \log \left(10^{\frac{L_{A B}}{10}}-10^{\frac{L_{B}}{10}}\right) d B A
$$

Where $\mathbf{L}_{\mathbf{A}}=$ LAeq, $6 \mathrm{hr}$ calculated for A, $\mathbf{L}_{\mathbf{A B}}=$ LAeq, $6 \mathrm{hr}$ measured at HAR, and, $\mathbf{L}_{\mathbf{B}}=$ LAeq, $6 \mathrm{hr}$ measured at HR.

\section{Results}

Table 2. LAeq, 6hr, LAmax, 6hr, and standard deviation at each site

\begin{tabular}{lcccccc}
\hline & HAR1 & HAR2 & HR & $\mathrm{H}^{*} \mathrm{~A}^{*}$ & $\mathrm{~A}$ & $\mathrm{C}$ \\
\hline LAeq, 6hr (dBA) & $75.6 \pm 0.33$ & $75.6 \pm 0.36$ & $72.9 \pm 0.35$ & $70.9 \pm 0.20$ & $63.1 \pm 1.52$ & $55.3 \pm 1.58$ \\
(number of days) & $(\mathrm{N}=4)$ & $(\mathrm{N}=4)$ & $(\mathrm{N}=4)$ & $(\mathrm{N}=4)$ & $(\mathrm{N}=4)$ & $(\mathrm{N}=2)$ \\
LAmax, 6hr $(\mathrm{dBA})$ & $82.5 \pm 0.97$ & $80.0 \pm 0.23$ & $77.0 \pm 0.58$ & $79.2 \pm 0.40$ & $72.2 \pm 1.83$ & $62.5 \pm 1.80$ \\
(number of days) & $(\mathrm{N}=4)$ & $(\mathrm{N}=4)$ & $(\mathrm{N}=4)$ & $(\mathrm{N}=4)$ & $(\mathrm{N}=4)$ & $(\mathrm{N}=2)$ \\
\hline
\end{tabular}

Table 2 shows that the LAeq, 6hr and LAmax, 6hr were highest at the HAR1 (75.6 dBA and $82.5 \mathrm{dBA}$, respectively) and HAR2 site (75.6 dBA and $80.0 \mathrm{dBA}$, respectively) where there were 3 principal sources contributing to the noise levels: air, road and train traffic. A similar pattern in LAeq, $6 \mathrm{hr}$ and LAmax, $6 \mathrm{hr}$ across the sites was observed. The HR site however exhibited a lower LAmax, $6 \mathrm{hr}(77.0 \mathrm{dBA})$ than the $\mathrm{H}^{*} \mathrm{~A}^{*}$ site $(79.2$ $\mathrm{dBA}$ ), a trend that was not apparent in the LAeq, $6 \mathrm{hr}$ results. The elevation of LAmax, $6 \mathrm{hr}$ values above LAeq, 6hr values ranged from 4.1 to $9.1 \mathrm{dBA}$.

Noise levels were quite similar between days, exhibiting consistently low standard deviations. This was particularly true at sites $\mathrm{H}^{*} \mathrm{~A}^{*}(0.20 \mathrm{dBA}$ and $0.40 \mathrm{dBA})$, HR $(0.35 \mathrm{dBA}$ and $0.58 \mathrm{dBA})$, HAR $10.33 \mathrm{dBA}$ and $0.97 \mathrm{dBA}$ ) and HAR2 (0.36 and 0.23) for LAeq, 6hr and LAmax, 6hr, respectively. Standard deviations were higher at sites $\mathrm{A}(1.52 \mathrm{dBA}$ and $1.83 \mathrm{dBA})$ and $\mathrm{C}(1.58 \mathrm{dBA}$ and $1.80 \mathrm{dBA})$, though still small.

A t-test confirmed that the difference between the means of site HAR1, which was sampled in the summer, and HAR2, which was sampled in the fall, was negligible for LAeq, $6 \mathrm{hr}(\mathrm{t}=0.0024 ; \mathrm{p}=0.9981)$. However, for the LAmax, $6 \mathrm{hr}$ indicator, the difference between HAR1 and HAR2 was not equal to zero $(\mathrm{t}=4.845 ; \mathrm{p}=0.01296)$. We thus combined the LAeq, $6 \mathrm{hr}$ from site HAR1 with that of HAR2 so as to obtain an overall LAeq, $6 \mathrm{hr}$ value for site HAR to be used in the remainder of the analysis. The combined LAeq, $6 \mathrm{hr}$ value for HAR based on values at HAR1 and HAR2 was $75.6 \pm 0.32(\mathrm{~N}=8)$. For analyses with the LAmax, 6hr indicator, the separated HAR1 and HAR2 values were used.

An ANOVA revealed that there was significant variability among the means of LAeq, 6hr at each of the sites HAR, HR, $H^{*} A^{*}$, A and $\mathrm{C}(\mathrm{F}=369.75, \mathrm{p}<0.01)$. Furthermore, post hoc pairwise t-tests also showed a significant difference between each pair of sites for this indicator $(p<0.05)$. For the LAmax, $6 \mathrm{hr}$ values, the ANOVA suggested that the means at the sites were different $(\mathrm{F}=127.21, \mathrm{p}<0.01)$. A subsequent pairwise comparison confirmed the results of the ANOVA for most comparisons $(\mathrm{p}<0.05)$, however, it did suggest that the means of $\mathrm{H}^{*} \mathrm{~A}^{*}$ and $\mathrm{HR}$, as well as of $\mathrm{H}^{*} \mathrm{~A}^{*}$ and HAR2 were not significantly different $(\mathrm{p}=0.1330$ and $\mathrm{p}=1.0000$, respectively). In addition, with the Bonferroni adjustment, the results of the pairwise comparison between HAR1 and HAR2 differed from the t-test, suggesting now that the difference between these two sites was not significant $(\mathrm{p}=0.0754)$. 
The LAeq, 6hr value calculated using Equation 1 for the airport contribution to site HAR was 72.3 dBA. Comparatively, the LAeq, 6hr level measured at site A was 63.1 dBA. There was therefore at least a 9.2 dBA discrepancy between the estimated contribution of airport noise to noise levels in these regions (given that the value measured at site A also reflects background noise levels).

Table 3. LAeq, LAmax, and standard deviation from four days of sampling at sites HAR1 and A with (P) or without (NP) an aircraft passing

\begin{tabular}{lll}
\hline Site & HAR1 & A \\
\hline LAeq, P (dBA) & $76.5 \pm 1.10$ & $67.0 \pm 2.06$ \\
LAeq, NP (dBA) & $75.4 \pm 0.42$ & $61.8 \pm 2.62$ \\
LAmax, P (dBA) & $85.0 \pm 3.16$ & $75.9 \pm 1.81$ \\
LAmax, NP (dBA) & $82.0 \pm 0.57$ & $71.0 \pm 2.87$ \\
\hline
\end{tabular}

The passage of aircrafts over site HAR1 raised LAeq, P by $1.1 \mathrm{dBA}$ and LAmax, P by 3.0 dBA above the noise levels when no aircraft was passing. Aircraft passage over site A raised LAeq, P and LAmax, P by 5.2 dBA and 4.9 dBA, respectively (Table 3 ).

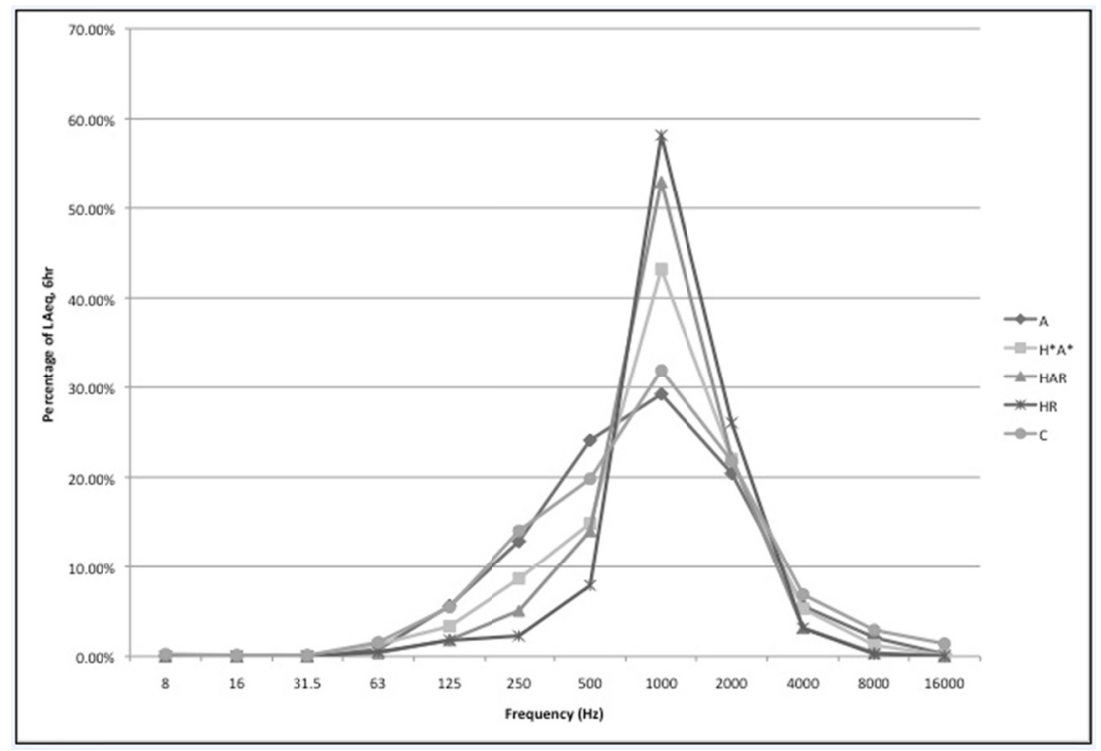

Figure 3. Relative frequency distribution of LAeq, $6 \mathrm{hr}$ at each site

Figure 3 shows that the frequency distribution is most broad for sites $\mathrm{A}$ and $\mathrm{C}$, followed by $\mathrm{H}^{*} \mathrm{~A}^{*}$, and lastly HAR and HR, both of which are concentrated quite narrowly at a frequency of $1000 \mathrm{~Hz}$. This frequency represents a peak for each of the other sites sampled as well. At $1000 \mathrm{~Hz}$, the HR peak exceeds that of HAR, and the $\mathrm{C}$ peak exceeds that of A. At $500 \mathrm{~Hz}$, the peak at site A exceeds all other sites, and the peaks at sites $\mathrm{H}^{*} \mathrm{~A}^{*}$ and HAR exceed that at site HR.

\section{Discussion}

Our study aimed to explore the contribution of transportation sources to environmental noise in the Dorval region of the international airport of Montreal. Our main findings were that noise levels were above optimal levels at each of the sites measured and that airport noise may contribute to a large portion of environmental noise in residential areas, roughly as much as two other transportation sources combined.

Where the NEF exceeds 30, as it does at sites HAR and A, Transport Canada (2012) suggests that residential development should not proceed. Residential housing however already exists within the NEF 30 zone of the Montreal International Airport; in fact, 2,150 persons were residing within this zone in 2009 (Boeing, 2011). Outside the NEF 30 contours at the Control site (C), equivalent noise levels were the lowest measured (55.3 
dBA). The World Health Organization Guidelines for Community Noise, suggest that daytime outdoor sound levels on balconies, terraces and outdoor living areas should not exceed either $55 \mathrm{~dB}$ LAeq or $50 \mathrm{~dB}$ LAeq in order to protect the majority of the population from being seriously or moderately annoyed, respectively (Berglund et al., 1999). Thus, even in terms of serious annoyance, these guidelines are exceeded at every site measured. Furthermore, these guidelines were developed based on responses from the average or "normal" person, and certain groups such as children, the elderly, the ill or the disabled may be at risk at even lower levels of exposure; they may also be less able to cope with environmental noise in general. However, it is important to note that our measurements were not conducted directly on residential properties and do not act explicitly to quantify noise levels to assess population exposure. Additionally, only two sites could be considered as residential sites (A and C). Finally, the WHO guideline for outdoor sound levels was developed based on an LAeq, $16 \mathrm{hr}$ indicator. Our results on the other hand were based on an LAeq, 6hr indicator. It is possible that the contribution of evening measurements would have resulted in lower LAeq values than those reported here.

During playtime, in the outdoor playgrounds of schools, it is suggested that sound levels from external sources should not exceed $55 \mathrm{~dB}$ LAeq (Berglund et al., 1999). The A site was located in proximity to a school and the equivalent noise level monitored was $63.1 \mathrm{dBA}$. When an aircraft passed, the LAeq, P reached on average 67.0 $\mathrm{dBA}$, and when no aircraft was passing, the LAeq, NP was much smaller (61.8 dBA), but still well above the WHO's recommendation of $55 \mathrm{dBA}$. The passage of individual flights were also able to raise noise levels in the summer at site HAR1, though not to the same extent as at site A, where noise levels when no aircraft was passing were not already elevated appreciably by highway and railway traffic. These results may be important in the context of evidence suggesting that intermittent patterns of noise output may foster greater disturbance than more constant sources. The RANCH study, for example, showed a direct link between aircraft noise and impaired reading comprehension in children that could not be paralleled by road traffic noise (Clark et al., 2005). Overall, when evaluated against public health standards, each of the measured sites appeared to be problematic, including sites $\mathrm{A}$ and $\mathrm{C}$, which are in residential areas.

The analysis of the LAmax, $6 \mathrm{hr}$ indicator suggested that for site HAR, there existed variability between summer (HAR1) and fall (HAR2) sampling events; this may suggest that aircraft noise is more predominant in the summer. The pairwise comparison that followed our ANOVA indicated, contrary to our expectations, that there was a negligible difference between the sites HAR2 and $\mathrm{H}^{*} \mathrm{~A}^{*}$, as well as sites HR and $\mathrm{H}^{*} \mathrm{~A}^{*}$. The LAmax, 6hr values indicate also that sites $\mathrm{A}, \mathrm{H}^{*} \mathrm{~A}^{*}$, and $\mathrm{C}$ experienced the greatest elevations in noise $(9.1 \mathrm{dBA}, 8.3 \mathrm{dBA}$ and $7.2 \mathrm{dBA}$, respectively) compared to their LAeq, $6 \mathrm{hr}$ values. This may be a reflection of the relatively lower LAeq, $6 \mathrm{hr}$ values used as a starting point at these sites, which would allow specific noise events to elevate noise levels considerably. Overall, LAmax, 6hr values were mostly consistent with the trend observed for LAeq, $6 \mathrm{hr}$ values, but one difference was that the trend for LAmax, $6 \mathrm{hr}$ was reversed at sites HR (77.0 dBA) and $\mathrm{H}^{*} \mathrm{~A}^{*}$ (79.2 dBA) (Table 2). This result may be explained by the non-significant difference found in the pairwise comparison between the means of $\mathrm{H}^{*} \mathrm{~A}^{*}$ and HR for LAmax, 6hr. However, it may also reflect a difference in the characteristics of aircraft noise compared to railway noise, another testament to aircraft noise's intermittency. Indeed, this feature is further emphasized when looking at the elevation of LAmax, 6hr above LAeq, $6 \mathrm{hr}$ at comparable sites HAR [6.9 dBA (HAR1); 4.4 dBA (HAR2)] and HR (4.1 dBA), as well as A (9.1 dBA) and C (7.2 dBA), the larger elevation of which contains an aircraft component in each case. It is apparent that aircraft noise represents an important contributor to the LAmax, $6 \mathrm{hr}$ indicator, which reflects peak noise events.

Unlike equivalent noise levels, the frequency distribution of environmental noise at the sites does not appear to be particularly problematic from a public health standpoint. Our results show a tendency for frequencies to be concentrated largely in the mid-range values at each of the sites. On the other hand, health effects tend to manifest in the extreme frequency ranges, particularly at low frequencies in the range of $10 \mathrm{~Hz}$ to $200 \mathrm{~Hz}$ (Leventhall, 2004). Importantly however, our results are A-weighted, meaning that low frequency noise is under-represented compared to its un-weighted form (Leventhall, 2004). Given that the WHO recommends that noise with low-frequency components should have lower exposure guidelines (Berglund et al., 1999), these results should be interpreted prudently.

At $1000 \mathrm{~Hz}$, a peak in noise levels exists for each of the sites measured. The HR peak here exceeds that of HAR and $\mathrm{H}^{*} \mathrm{~A}^{*}$, and the $\mathrm{C}$ peak exceeds that of $\mathrm{A}$. This result may suggest that airport noise has a greater influence at other frequencies while other traffic sources, particularly rail, contribute largely to $1000 \mathrm{~Hz}$. For example, at 500 $\mathrm{Hz}$, the A site exceeds all other sites, and the $\mathrm{H}^{*} \mathrm{~A}^{*}$ and HAR sites exceed the HR site. Thus, aircraft noise may be an important contributor to this frequency.

In residential areas, our results suggest that the contribution of airport noise to environmental noise levels is highly variable. Noise levels measured at site A were $63.1 \mathrm{dBA}$. This value reflects an airport contribution as 
well as background noise, but no other major transportation sources. Comparatively, the estimated contribution of airport noise $600 \mathrm{~m}$ closer the airport at site HAR was $72.3 \mathrm{dBA}$ (Equation 1). Thus, a comparison of these two values suggests that the contribution of airport noise at site HAR is at least $9.2 \mathrm{dBA}$ higher than that at site A. This large discrepancy may not be adequately explained by differences in highway or railway traffic at the two sites compared. We suggest that it may also be accounted for by airport activities and operations other than flights, as well as the greater elevation of aircrafts on their flight paths at site A. Since the HAR site is located $600 \mathrm{~m}$ closer to the airport than the A site, it is in a better position to be exposed to noise from airport operations such as parking lot activities, access road traffic, public transportation stations, and other factors not accounted for in the NEF 30 calculations. In addition, the contribution of flights alone at site HAR may be somewhat greater due to site A's location, which is closer to the boundaries of the NEF 30 zone and $600 \mathrm{~m}$ farther from the airport. This greater distance from the airport allows flights to reach a higher elevation at site A and thereby increase ambient noise levels to a lesser extent. To put this calculated value for the airport noise contribution at site HAR (72.3 dBA) into context, it can be compared to the value measured at site HR (72.9 dBA). The noise levels measured at the HR site roughly equate the level of background noise (compared to airport noise) at the HAR site; thus, these results suggest that the contribution of airport noise is roughly as large as the contribution of two other major noise sources: highway and railway traffic.

The strategy of aircraft noise quantification above background levels presented here represents a less fastidious and time consuming alternative to the use of microphone arrays, as suggested by Genescà et al. (2009). Our study, however, was not free of limitations. Our measurements were taken exclusively during the daytime and so potentially important data on nighttime noise is missing. Another possible drawback was the combination of summer and fall data. Previous studies have suggested that seasonal variation may exist in environmental noise levels, perhaps due to variations in flight numbers (Berglund et al., 1999). In the present study, such a difference was observed for the LAmax, 6hr indicator. However, an important secondary finding of our study is the representativity of our results for equivalent noise levels. The agreeability between sites HAR1 and HAR2 for the LAeq, $6 \mathrm{hr}$ indicator suggested a lack of fall versus summer variability in equivalent environmental noise levels for the year studied. Similarly, a lack of day-to-day variability in noise measurements was observed, indicated by the consistently low standard deviations for both indicators at all sites. Although this low variability may indicate that this limitation is minor, it should be noted that days with rain or snow were not considered in this study, which restricts the generalizability of this result.

Another consideration is that our results were based on the assumption that the highway and railway contributions to sites HR and HAR were equal. Due to a variety of site factors, this may not necessarily have been the case. Our study would have benefitted from an additional Highway $(\mathrm{H})$ and/or Railway (R) site that lacked contribution from other transportation activities. Of course, this was not possible given the setting. Prospective studies around different airports should look for such sites where possible to allow for a more practicable comparison.

We recommend that future studies assess both indoor and nighttime noise levels in proximity to traffic sources, and also that socioeconomic inequalities within the exposed groups be considered. Finally, as just one of many factors in the impact of transportation sources on the environment, noise pollution should be studied in the context of other pollutants (e.g. air) to gain a more holistic conception of the influence of these sources.

\section{Conclusion}

Our study suggests that near the Montreal International Airport, noise sources other than aircrafts, such as railways and highways, may be important contributors to environmental noise levels. However, close to the airport, the estimated contribution of airport noise was roughly equal to that of these two other transportation sources combined. In this area, noise levels may be elevated by airport operations in addition to noise from flights, the former of which is unlikely to be a contributing factor at farther distances from the airport. At farther distances however, aircraft passages can be observed to raise noise levels to a greater extent above levels when no flight is passing, reflecting a sporadic quality of aircraft noise that may be more annoying than noise from other sources. Expectedly, noise levels were found to be the highest where there were three contributing transportation sources. However, at all sites measured, the WHO's noise exposure guidelines of $55 \mathrm{dBA}$ were exceeded, including those sites located in residential areas or near a school.

\section{Acknowledgments}

We would like to acknowledge Allan Brand for his contribution of the map of Montreal. 


\section{References}

Barron, R. F. (2003). Industrial noise control and acoustics. New York, NY: Marcel Dekker, Inc.

Berglund, B., Lindvall, T., \& Schwela, D. H. (1999). Guidelines for Community Noise. Geneva: World Health Organization.

Boeing. (2011). Airport noise and emissions regulations. Retrieved July 17, 2013, from http://www.boeing.com/commercial/noise/dorval.html

Clark, C., Martin, R., van Kempen, E., Alfred, T., Head, J., Davies, H. W., ... Stansfeld, S. A. (2005). Exposure-effect relations between aircraft and road traffic noise exposure at school and reading comprehension. Am J Epidemiol, 163, 27-37. http://dx.doi.org/10.1093/aje/kwj001

Fields, J. M., \& Walker, J. G. (1982). Comparing the relationships between noise level and annoyance in different surveys: A railway noise vs. aircraft and road traffic comparison. J Sound Vib, 81, 51-80. http://dx.doi.org/10.1016/0022-460X(82)90177-8

Genescà, M., Romeu, J., Arcos, R., \& Martín, S. (2013). Measurement of aircraft noise in a high background noise environment using a microphone array. Transportation Research Part D, 18, 70-77. http://dx.doi.org/10.1016/j.trd.2012.09.002

Genescà, M., Romeu, J., Pàmies, T., \& Sánchz, A. (2009). Real time aircraft fly-over noise discrimination. J Sound Vib, 323, 112-129. http://dx.doi.org/10.1016/j.jsv.2008.12.030

Genescà, M., Romeu, J., Pàmies, T., \& Sánchz, A. (2010). Aircraft noise monitoring with linear microphone arrays. IEEE Aerospace Electron Syst Mag, 25, 14-18. http://dx.doi.org/10.1109/MAES.2010.5442149

Haralabidis, A. S., Dimakopoulou, K., Vigna, T. F., Giampaolo, M., Borgini, A., Dudley, M. L., ... Jarup, L. (2008). Acute effects of night-time noise exposure on blood pressure in populations living near airports. European Heart Journal, 29, 658-664. http://dx.doi.org/10.1093/eurheartj/ehn013

Leventhall, H. G. (2004). Low frequency noise and annoyance. Noise \& Health, 6, 59-72.

Passchier-Vermeer, W., \& Passchier, W. F. (2000). Noise Exposure and Public Health. Environ Health Perspect, $108,123-131$.

Perron, S., Tétreault, L. F., King, N., Plante, C., \& Smargiassi, A. (2012). Review of the effect of aircraft noise on sleep disturbance in adults. Noise \& Health, 14, 58-67. http://dx.doi.org/10.4103/1463-1741.95133

Stansfeld, S., \& Crombie, R. (2011). Cardiovascular effects of environmental noise: Research in the United Kingdom. Noise \& Health, 13, 229-233. http://dx.doi.org/10.4103/1463-1741.80159

Stansfeld, S., Hygge, S., Clark, C., \& Alfred, T. (2010). Night time aircraft noise exposure and children's cognitive performance. Noise \& Health, 12, 255-262. http://dx.doi.org/10.4103/1463-1741.70504

Stansfeld, S. A., Berglund, B., Clark, C., Lopez-Barrio, I., Fischer, P., Öhrström, E., ... Barry, B. F. (2005). Aircraft and road traffic noise and children's cognition and health: a cross-national study. Lancet, 365, 1942-49. http://dx.doi.org/10.1016/S0140-6736(05)66660-3

Transport Canada. (2012). Noise exposure forecast and related programs. Retrieved July 18, 2013, from http://www.tc.gc.ca/eng/civilaviation/standards/aerodromeairnav-standards-noise-nef-924.htm

Transports Québec. (2010). Atlas des transports: Débits de circulation. Retrieved July 17, 2013, from http://transports.atlas.gouv.qc.ca/NavFlash/SWFNavFlash.asp?input=SWFDebitCirculation_2010

\section{Copyrights}

Copyright for this article is retained by the author(s), with first publication rights granted to the journal.

This is an open-access article distributed under the terms and conditions of the Creative Commons Attribution license (http://creativecommons.org/licenses/by/3.0/). 